\title{
Progress on the global photonics education network
}

\section{Marc Nantel}

Marc Nantel, "Progress on the global photonics education network," Proc. SPIE 9664, Ninth International Topical Meeting on Education and Training in Optics and Photonics, 966404 (24 October 2005); doi: 10.1117/12.2207716 and Photonics, 2005, Marseille, France 
Ref ETOP055

Progress on the Global Photonics Education Network (GPEN)

\author{
Marc Nantel
}

Photonics Research Ontario (a Division of OCE Inc), Toronto, Ontario, Canada

\begin{abstract}
Since ETOP 2001, the Global Photonics Education Network (GPEN) has slowly formed and built momentum. With its growing number of members, its list-serv email address and a new webpage, the GPEN is gathering the critical mass needed to become a useful tool for photonics educators worldwide. This paper will recap the evolution of the GPEN so far, present its current state (including the webpage), emphasize the role of "clusters" for its health and suggest the next steps to take to firmly establish it as an essential part of the photonics education and training community.
\end{abstract}

\title{
Keywords
}

photonics, education, training, networking, global, cluster

\section{Introduction}

\section{Summary}

An educator in photonics has a question about curriculum development, about the way to best convey a particular concept (in lectures or in the lab), about which book to use for a new course to mount or a continuing one just taken over. Where does one start? With the people one knows, those in the department or collaborators from other institutions. If this doesn't provide the information needed, one can follow it up with a web-search and a literature search. This progression can be somewhat limiting, time-consuming and tedious. Information is important, but knowing where to get it and actually having a dialogue with the source of this information is even more important. What if one could tap into a large reservoir of knowledge and experience in one's field just by sending an email? This could certainly be useful.

Networking is done at many levels, in many fields. A "network" according to the meaning here is a web of interconnected people sharing an interest in the success of a particular enterprise. Photonics educators can benefit from being better connected to each others, not just to information. These connections should happen through all levels (from grade school to grad school). Continuing education and science \& technology outreach should be included, as well as funding agencies, industry and any player with a stake in the success of physics education as a whole. It helps for these connections to have a particular subject or emphasis in common to focus the motivations of the various participants. ${ }^{1}$ This paper presents the progress of the Global Photonics Education Network that first formed as a result of a discussion at ETOP 2001 in Singapore. 


\section{Birth of the Global Photonics Education Network (GPEN)}

As part of the Education and Training in Optics and Photonics (ETOP) conference held in Singapore in November 2001, a panel discussion entitled "Global Networking to Promote Local Technician Education - Problems and Solutions" was held. Members from 9 countries exchanged view on the subject and agreed to form a global network to address local issues in photonics education and training. This led to the creation of the Global Photonics Education Network (GPEN), an example of networking on a worldwide scale. The Panel generated a report that was published in the ETOP 2001 proceedings and generated the recommendations ${ }^{2}$, including setting up a global network for educators (done: the GPEN), involve new members from clusters worldwide (in progress), and conduct surveys of various needs with the help of the professional societies and the clusters (still in the future). Since the Panel, a discussion forum was graciously provided by SPIE on their webpage (http://spie.org/app/forums/, and then "Technician Education") and a list-serv email address was established to facilitate exchanges between GPEN enthusiasts. A GPEN draft plan was written and suggests a possible way to go for the Network, and it was discussed at several international meetings. The plan is available on the SPIE discussion forum or through the author.

\section{Importance of "clusters" for the GPEN}

One recurring theme from the first Roundtable Panel discussion and subsequent exchanges dealt with the crucial role clusters could take in the formation and operation of the GPEN. It seems clear that a well organized Global Network in photonics education would be most useful if it can facilitate the access to all the diversity of global best practices to the local educational leaders explicitly interested in strengthening the business base of the local photonics industry clusters. Because of the inherently local nature of industry clusters, the GPEN, by virtue of its vision of providing the global photonics education infrastructure, could be the facilitator to build a "cluster of clusters", or a "supercluster", to borrow a term from our colleagues in astronomy. The establishment of a local cluster requires some critical mass of industry and academic institutions interested in photonics and the dedication of a few individuals to organized and maintain it. This means that the GPEN should inspire academics, industry engineers and scientists to participate in GPEN activities that promote their local interests through their local or international societies. By promoting excellence in local technical and advanced education, by providing easy access to sharing global best practices, the GPEN will naturally facilitate the start and growth of local photonics industry clusters. The GPEN can provide useful resources to new and existing local chapters of SPIE, OSA, IEEE, etc., which, in turn, nurture local industry clusters. However, more focused organizations designed specifically to promote local photonics education for the specific purpose of accelerating the growth of local photonics industry would be an important approach for many countries. One should note that most of the original participants of the 2001 Roundtable meeting are local education leaders and are involved in organizing and promoting photonics education in many new ways to reach out beyond the needs of their immediate institutions.

\section{Vision and Mission}

The draft Vision and Mission for the Global Photonics Education Network are outlined below. They are not written in stone and are subject to change. Partly, this is because it should be the membership who sets them and this is slowly building. First, establish communications links, then populate them with interested parties, set up a loose governance structure and THEN proceed to lay down the organizational principles on which the GPEN will rest. The Vision and 
Mission statements, as well as goals and deliverables, are best set by the people who will populate the network, not just the few who are keeping it greased and in working order.

Vision: The Global Photonics Education Network (GPEN) will endeavour to support the implementation and enhancement of optics/photonics education and training programs worldwide by enabling support networks among educators, industry and government.

The GPEN will achieve its Vision through following its five Mission statements:

1. Facilitate the development of local photonics education clusters in support of GPEN and of local photonics educators;

2. Provide a networking opportunity for photonics educator with their colleagues from around the world;

3. Facilitate the free exchange and circulation globally of curriculum ideas, standards, aids and experiments;

4. Promote the spread of distance education in photonics (web-based or otherwise) to bring photonics education to all areas of the world, including to those below the critical mass to mount their own programs;

5. Facilitate the formation of a united voice for the global photonics education community out of the locally diverse needs at different levels.

\section{Going forward}

With these bases set in place, the next important steps to take are to recruit and involve the membership in the GPEN, to breathe life into it and make it a useful tool for educators worldwide. It is difficult to make a project like this move forward at the beginning partly because the GPEN is so diffuse, and partly because little happens unless it is featured at the top of someone's list of priority. That has certainly been the case for the GPEN since 2003. Similarly, at ETOP 2003 in Tucson, AZ (USA), a call for action for a webpage that could serve as a resource was made by Alexander Sawchuk (Chair of the International Commission for Optics' Education Committee $)^{3}$ but it is unclear what has been accomplished to date. With proper coordination and with everyone pulling in the same direction, serious and growing momentum can be garnered toward advancing the cause of networking photonics educators worldwide. The GPEN can participate in this effort and, in order to shift the process into the next gear, is currently putting together a webpage of programs and other links in photonics education. This webpage will be found at: www.globalphotonicseducationnetwork.org and should be live in time for ETOP 2005 in Marseilles, France.

With an action plan, a list-serv, a website and good communications with ICO and other international photonics associations (SPIE, OSA, IEEE,...), all will be in place to make GPEN a success. It will be incumbent on the membership to realize this potential.

\section{Acknowledgements}

The author would like to acknowledge funding from the Strategic Skills Investment Program or the Ontario Ministry of Economic Development and Trade.

\section{References}

1) M. Nantel, On the importance of networking in physics education: multiple heads are 
better than one, Phys. Can. 61, 91 (2005); M. Nantel, OPETA and GPEN: models for local and global networking, SPIE Proc. 5578E (2004).

2) C. Roychoudhuri, Global Networking to Promote Local Technician Education - Problems and Solutions, in Seventh International Conference on Education and Training in Optics and Photonics, T K Lim, ed., SPIE Proc. 4588A (2001).

3) A.A. Sawchuk and A.H. Guenther, The Role of the International Commission for Optics (ICO) in Optics Training and Education, in Education and Training in Optics and Photonics (ETOP) 2003 Conference Technical Digest, Tucson, AZ, paper EMB1, Optical Society of America, Washington, DC, 2003. 